\title{
Globalization and Assessement of the Soft Power Potential of Belarus Using Econometric Instruments
}

\author{
Olena Primierova ${ }^{1, *}$, Juliet Abakumova ${ }^{2}$ \\ ${ }^{1}$ National university of Kyiv-Mohyla academy, Faculty of Economics, Department of Finance, \\ Skovorody 2, 04070 Kyiv, Ukraine \\ ${ }^{2}$ Belarusian state university, Economics Faculty, Department of Analytical Economics and \\ Econometrics, K.Marks 31, 220030 Minsk, Belarus
}

\begin{abstract}
.
Research background: When it comes to conducting international events in a country with a small open economy, the issue of assessing the ratio of costs of the event to subsequent economic effects is relevant. If the evaluation of short-term revenues in the country is quite realistic, then quantifying the long-term effect on a country's image is much more difficult, and directly related to the concept of soft power and its evaluation as a neutral instrument in international relations. The study was based on the concept of soft power and its instrument, such as the international image of the state, the improvement of which is possible by conducting various events of an international level.

Purpose of the article: The opportunity was of interest to assess the effect of using one of the neutral tools of the so-called soft power, such as holding international sports events.

Methods: To test hypotheses, time series models were used on the example of Belarus data. Also, for Belarus, the Soft Power Index was calculated according to the methodology of the Moscow School of Management Skolkovo and the British audit and consulting company Ernst and Young. Findings \& Value added: The conclusion is confirmed that the holding of sports events of an international scale directly affects the increase in indexing in the search queries of keywords characterizing the country, which in turn through the components of the globalization index positively affects its values for the country. Also, the holding of sports and cultural events has a positive effect on the influx of foreign tourists into the country.
\end{abstract}

Keywords: soft power; country image; international events; globalization index; econometric models

JEL Classification: $C 01 ; F 59 ; Z 19$

* Corresponding author: o.primierova@ukma.edu.ua 


\section{Introduction}

The concept of soft power first appeared in the 1980s in the work of the renowned American political scientist, leading expert on international relations, as well as Professor of the Harvard Institute of Public Administration Joseph Nye. In his speeches and publications, he gave several definitions of soft power at once. For example, soft power is the ability to shape the preferences of others, or the ability to make others want what you want by being drawn to your culture and ideology. Or the ability to influence other states in order to realize their own goals through cooperation in certain areas, aimed at persuading and forming a positive perception. He also spoke about the fact that the soft power of the country is a key element of governance and relies on resources of culture, values and politics $[1,2]$.

At the moment, there is no single definition accepted throughout the world. But speaking in the most general terms, soft power is an instrument of covert management of international processes in the era of globalization, using the most delicate means of persuasion: diplomacy, programs of international exchange of specialists, cultural and sports events, etc.

There are two ways to promote the state's image abroad: natural and artificial. In the first variant, the state "automatically" improves its image in the international arena thanks to successes in the economy, the development of culture, the legitimacy of politics carried out inside the state and outside it, as well as thanks to the achievements of the scientific sphere. When artificially promoting the country's image, it is planned to carry out various measures: advertising, informational, which are aimed at improving the international image of the state, i.e. we are talking about a purposeful and deliberate policy of soft power. The effective use of soft power tools creates opportunities for the state-subject to influence political and humanitarian processes in the state-object of influence and in the world as a whole. Among the main instruments, one can also mention the education system, including university rankings, academic mobility programs, tourism and sports, and migration policy.

\section{Methods and Results}

\subsection{Methods for assessing soft power}

The need for a formalized assessment of socio-economic processes is due to objective trends in world development. To make a real assessment of the state and prospects of socioeconomic development, the indicator approach is most often used: to compare the achievements of the countries of the world, various indices are used, some of which assess specific areas of activity, while others represent a comprehensive assessment of several areas and spheres $[2,3]$.

There are two well-known and proven approaches: the National Brands Index and the Country Brands Index. The National Brands Index was developed by Simon Anholt [4], an independent political advisor on building the country's national brand image, national identity and reputation in 2005. If at first the index was calculated for 35, now the list includes 50 countries of the world. The indicator value is determined based on six indicators: export (determines public opinion regarding the goods and services offered by the country); governance (reflects public opinion on the level of competence of national governments and justice); culture and heritage (reveals the global perception of the heritage of each country and world recognition of its modern culture); people (measuring the reputation of the population in matters of competence, education, openness and friendliness, as well as various levels of discrimination); tourism (covers the level of interest in visiting the country); investment and immigration (determines the ability to attract people to live, work or study). 
In 2017, Germany, France, Great Britain, Canada, Japan, USA, Italy, Australia, Switzerland, Sweden entered the top 10 countries (countries are listed in order from 1st place in the ranking to 10). In the course of compiling the rating, 20185 people over 18 years old from 20 countries were interviewed. Unfortunately, the Republic of Belarus was not included in the list of 50 studied countries, however, some neighboring countries (Russia, Ukraine and Poland) were included in the rating. So, for example, Russia took 23rd place in the list of the most powerful national brands.

The next well-known indicator is the Country Brand Index, developed and calculated every few years (2012, 2014 and 2019). It is published by the international consulting company Future Brand. During the last survey, 2,500 experts from countries included in the ranking were interviewed. At the same time, a total of 75 leading countries in terms of GDP were included, based on data from the World Bank. Unfortunately, Belarus again did not make it to the list, and the neighboring countries: Russia, Ukraine and Poland got in and took the 27th, 44th and 74th places, respectively. In 2019, the methodology for calculating the index slightly changed and if earlier it was based on 5 groups of indicators, now it is based on 6 main ones: value system, quality of life, business potential, heritage and culture, tourism, quality of products and services. There is an opinion that this index has a "tourist" bias, since the respondents are people who are somehow connected with travel.

In addition, in 2015, there was another new way to measure soft power. The international consulting company Portland has published a rating of the soft power of the states of the world called "The Soft Power 30". Since 2015, this rating has been calculated and published annually. The peculiarity of the calculation methodology is that 2 parts are taken into account: objective and subjective. The objective part is built from sub-indices in 6 categories: culture, digitalization, education, business and entrepreneurship, and public administration. The subjective part is the conduct of surveys (in 2018 among 11,000 respondents) in 7 categories: the spread of culture on an international scale, the production of luxury goods, high-tech products, national cuisine, vitality, friendliness, politics in the field of international relations. In 2018, the following countries were in the top 10: Great Britain, France, Germany, USA, Japan, Canada, Switzerland, Sweden, Netherlands, Australia. Despite the fact that this index of soft power resources as recognized by J. Nye, it is also often criticized [5].

One of the attempts to take into account all factors, creating a quantitative index reflecting the "soft power" of states, was undertaken by the Moscow School of Management Skolkovo and the British audit and consulting company Ernst and Young in the work called "Rapidgrowth markets soft power index" [6]. The proposed Soft Power Index combines a wide range of indicators that are grouped into groups of image, reputation, integration, and each of which has its own weight in the group.

Using the method developed by Skolkovo and Ernst and Young, the soft power index was calculated for Belarus and neighboring Ukraine for 2015 and 2019, which will allow both countries to be compared with each other and to consider one country in different periods. The initial data on the basis of which the Soft Power Index was calculated have some peculiarities. In the first group of indicators: the export of media products is represented by the volume of exports of advertising and other types of media products. Interest in learning the country's language is expressed in the total number of foreign students studying in Belarus and Ukraine. And although it cannot be argued that all of them have the goal of learning Russian or Belarusian, however, for most of them, throughout the entire training, classes are conducted on the study of the state languages. The number of Olympic medals won for 2015 is expressed in terms of medals won at the 2014 Winter Olympics in Sochi, and for 2019 at the PyeongChang 2018 Winter Olympics.

This is followed by the representation of the country's citizens in the Top 100 of Time magazine and the representation of companies in the Fortune-500 or Global-500 of Fortune magazine. And although not a single person from Ukraine or Belarus was included in the lists 
of the Time magazine neither in 2015 nor in 2019, in 2019 the President of Ukraine for the first time in history got on the cover of this prestigious publication, so this event was taken into account and included in the data for calculation of soft power. The total weight of the first group of indicators is 29.75 out of 100 .

The second group contains four indicators with a total weight of 29.75 out of 100 . The first of them is the Rule of Law Index, which is calculated annually by the non-governmental non-profit international organization The World Justice Project (WJP). The 2019 Index is based on surveys of more than 130,000 households and 4,000 expert surveys in 128 countries. The Index of Freedom is taken as the index of economic freedom, based on 10 factors and calculated annually by The Heritage Foundation, a US strategic research institute that deals with a wide range of research on international politics. Next, it is necessary to evaluate the voter turnout as a percentage of the turnout. In 2015, presidential elections were held in Belarus, and in 2019 - elections of deputies of the House of Representatives of the National Assembly of the VII convocation. In 2015, regional elections were held in Ukraine in 2 rounds, therefore, the arithmetic average of two voter turnout indicators was taken as the main indicator $(46.6 \%$ in the 1 st round and $34.1 \%$ in the 2 nd round, which was an anti-record in the entire history of sovereign Ukraine). In 2019, Ukraine also hosted presidential elections. Another indicator in the group, carbon dioxide emissions, is estimated in tonnes per person.

In the third group there are also four indicators, but the total weight is much higher than in the first or second groups -40.5 out of 100 . The volume of inbound migration is expressed in international migration growth / decline, and the volume of inbound tourism in the total number of people who visited countries and is based on data from the World Tourism Organization. The following is the number of universities in the prestigious Times Higher Education ranking, in Belarus in 2019 only one was awarded such an honor - the Belarusian State University. The last indicator is the English proficiency index according to Education First (EF), one of the largest educational companies operating in 114 countries. Since all indicators have different units of measurement, it became necessary to normalize. The result of calculating the index as the sum of the products of normalized indicators and the corresponding weight values is shown in the diagram (Fig. 1).

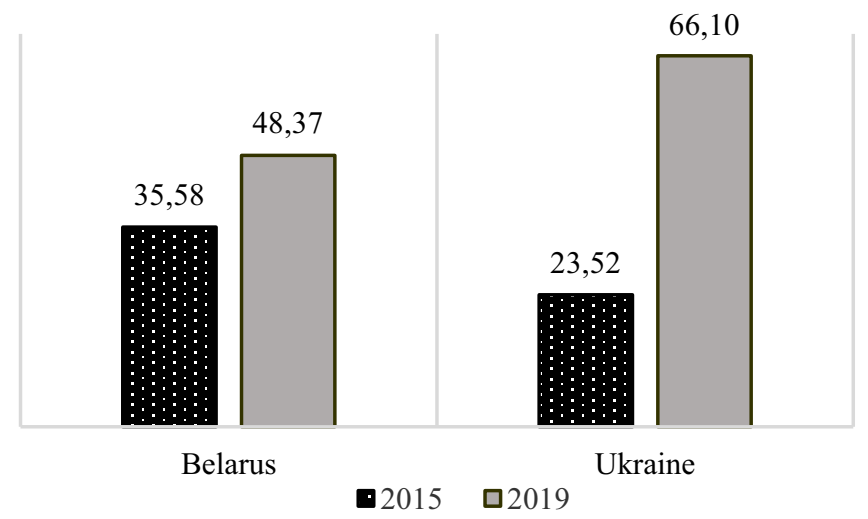

Fig. 1. Soft power index of Belarus and Ukraine.

Based on the results obtained, it can be concluded that among the observed countries or periods, the least use of soft power was in Ukraine in 2015. This may be due to many factors: there was a change of power in 2014, which some international experts even called a coup d'etat, which not only affected the overall reputation of the country, but also scared off many students wishing to study there, tourists, foreign businesses, reduced confidence in authorities and reduced inbound migration. In Belarus, the corresponding index is 12.1 points higher and 
is achieved due to high values of the following indicators: medals won at the Winter Olympic Games in Sochi (including 5 gold ones), migration gain and a high value of the rule of law index.

In 2019, the situation has changed significantly. Although both in Belarus and in Ukraine the index values increased, but if in Belarus the index increased by $35.96 \%$ compared to 2015 , then in Ukraine there was a much more significant growth $-181.28 \%$. This was achieved due to a large increase in international inbound migration and tourism in Ukraine, 4 universities were included in the Times Higher Education rating, and it was also influenced by the hit on the cover of Time magazine by Volodymyr Zelensky.

For Ukraine as a whole, the situation is different. So in 2015, the strongest influence was exerted by indicators of the volume of inbound tourism (42.17\%); note that despite the conduct of hostilities in the east of Ukraine, as well as the general unstable situation, the volume of entering foreigners was very high - almost 13 million people), the level of English proficiency (31.89\%) and the number of foreign students (13.93\%). In 2019, as in the case of the Republic of Belarus, the number of indicators, the share of which is $0 \%$, decreased. The dominant indicators with their respective shares were: migration growth, the volume of inbound tourism and the number of universities in the Times Higher Education ranking (all $16.64 \%$ each), hitting the cover of Vladimir Zelensky's Time magazine $(11.35 \%)$ and the level of English proficiency (9.26\%).

\subsection{Empirical assessment of the impact of soft power instruments}

The tasks of quantitatively assessing the effectiveness of the use of soft power instruments lie not only in the analysis of various ratings and country indices. But then the question arises of choosing indicators both for assessing efficiency and for taking into account the factors through which soft power manifests itself. The last statement follows from the fact that if the positive effects of improving the perception of a country in the world market are not in doubt, then the next thing to touch on is how a country can form its own brand that promotes such perception. The selection of factors can be based on the same list of indicators that is used to compile country brand ratings, but in this case, each of the directions or areas is supposed to be studied separately. If we consider the most common approaches, then, for example, Bloom Consulting Country Brand Ranking compiles a rating of countries in two editions: trade and tourism.

So, in their publications A. Rose showed on the basis of the gravity model that countries receive a commercial return on their soft power. This conclusion follows from the fact that according to the model: country's exports are higher if it is perceived by the importer to be exerting more positive global influence. The author came to this conclusion based on the construction of the gravity model for 2006-2013, using annual survey conducted for the BBC by GlobeScan which asks people in up to 46 countries. A similar conclusion was drawn from the data of annual Gallup survey for 2006-2017 for 157 countries: a 1\% increase in leadership approval raises exports by around two-thirds of a percent. In the first study a one percent net increase in perceived positive influence raises exports by around 0.8 percent $[7,8]$.

In [9] to estimate relationship between soft power and exporters behavior in international trade author also used gravity model and data with the BBC-GlobeScan and Pew surveys about people's opinion on exporter countries. The author concludes that there is a statistically significant effect soft power on exporting firms behaviors, essentially for some developping countries. However, he recognizes these results as more significant only on aggregate level of trade.

In the reviewed publications, efficiency is assessed through the country's success in foreign trade relations. Also, a sufficient number of publications are devoted to assessing the impact on the image of the state of the policy in the field of education [10], the level of 
development of sports in the country and achievements at international competitions [11, 12]. Countries with small open economies such as Belarus are trying to implement the concept of soft power, often using these two instruments. At the same time, it is in relation to the validity and effectiveness of the use of the second, as a rule, there are ambiguous assessments from the side of public opinion. Therefore, it was decided to consider the issue of researching a mechanism that is less studied using instrumental methods, namely, the presence of a response to various international events (competitions, exhibitions) from the tourism sector, which is also taken into account in the Country's Brand Index, and the Globalization Index.

The conclusions that the researchers receive, among other things, explain why developing countries participate in international competitions, despite the disputes regarding the need for associated costs in conditions of limited budgets [13]. Based on the concept of soft power, developing states are making attempts to transform their state image and strengthen their international position through major sporting events. It can also be noted, both in relation to developing and developed countries, that they often adhere to different soft power strategies and do not always use them to improve their image [14, 15].

A distinctive feature of sport in the context of globalization is its obvious institutionalization in a market economy and information society. We are talking about sports politics and sports diplomacy, since at the international level, sports are actively used for ideological and political purposes. The mechanisms of sports diplomacy and politics include [16]: image creation; creating a platform for dialogue; building trust; and reconciliation, integration and anti-racism. Sport is becoming one of the country's strategic tools and acts as a mechanism for non-administrative impact on public perception. Sport can be used as tool of soft power both internationally and domestically. The branding of the Olympic movement and the actualization of sports identity can be considered as examples of ways to obtain reputational dividends and promote a country on the world stage. Similarly, at the level of the internal policy of the state, sport is of great strategic importance for the management and development of regions.

One of the tools of soft power is the holding of international sports events. Sports events can be classified as neutral events. Most often they do not carry new ideas and do not convey the specific values of a particular state. The values that are disseminated with the help of this tool are universal, these are the values of health and beauty of an athletic body. Such values are generally recognized, recognizable and "native" for the overwhelming majority of people, i.e. are perceived positively. This instrument of soft power, broadcast through sports and sporting events, the commitment to a healthy lifestyle is a neutral and extremely "soft" way to increase the influence, including of an economically weak country, on the international arena.

As an information base for the empirical analysis, data for Belarus were chosen, which in recent years has demonstrated a constant interest in holding and participating in various sports events of an international scale. So, in 2014, the World Ice Hockey Championship was held in Minsk, and in 2019 - the II European Games. Until recently, Belarus was considered as a country that will host the World Ice Hockey Championship in 2021. Also, according to the obtained estimates of the soft power index, Belarus, out of the two considered countries, needs to improve the indicators of the country's image.

\subsubsection{Hypothesis 1: Assessing the Impact of Soft Power Instruments on Attracting Interest to the Country Through the Growth of the Tourism Industry}

One of the proofs of an effective policy on soft power may be that the country is interesting to other countries, that its natural, cultural and other characteristics are able to attract tourists. Therefore, it was in this direction that the empirical assessment of the impact on soft power (in the form of the volume of inbound tourism) of international sports tournaments held by 
the Republic of Belarus was initially considered, as well as participation in international exhibitions in two areas: scientific and tourism.

Thus, data on the volume of foreigners who visited the Republic of Belarus for tourist purposes were selected as the endogenous factor $Y_{t}$. Note that compared to 2010, when this indicator was 120.07 thousand people, in 2019 the indicator reached 405.50 thousand people, which means an increase in the flow of foreign tourists by more than 3 times. As one of the exogenous factors, namely $\mathrm{X}_{1 \mathrm{t}}$, the number of major international tournaments held in the Republic of Belarus was taken. Their number has grown even more significantly - almost 6 times. As a second factor $\mathrm{X}_{2 \mathrm{t}}$, considered data on the number of international exhibitions of the National Academy of Sciences of Belarus, including those held in Belarus and participation in foreign exhibitions; the number of international tourism exhibitions in which the Republic of Belarus took part was also taken into account.

Verification of the resulting model (1) for statistical adequacy and compliance with the OLS assumptions showed that the residuals of model are homoscedastic (White's test) and uncorrelated (DW statistics and correlogram analysis), and there are no specification errors in the model (RESET). To improve the statistical quality, the additive outlier variable in 2016 was introduced into the model and the constant was excluded. The overall statistical quality of the model is also satisfactory: the coefficient of determination $\mathrm{R}^{2}=0.93$ is statistically significant, the coefficients for exogenous variables are statistically significant at $\alpha=0.02$.

$$
\begin{aligned}
& Y_{t}=2.375 X_{1 t}+3.999 X_{2 t}-72.79 d_{2016} \quad R^{2}=0.93 \\
& \begin{array}{llll}
(P) & (0.014) \quad(0.019) & (0.074)
\end{array}
\end{aligned}
$$

Analysis of the model (1) shows that, firstly, there really is a connection between the instruments of soft power, in this case in three areas: sport (international competitions held in Belarus), science (exhibitions held or supported by the National Academy of Sciences of the Republic of Belarus) and tourism (the number of international tourism exhibitions in which Belarus participated) - and the result of soft power - the number of people who are somehow interested in the Republic of Belarus, including business interest, passion for culture or ideology.

Secondly, as can be seen from the statistics and already based on the confirmed connection, we can conclude that these tools really work. Through competitions and exhibitions, foreigners learn more about the achievements of the Republic of Belarus, about traditions and history, about the level of development of science and tourism opportunities, which increases interest in the country and entails an increase in the flow of inbound tourism. And here it is important to mention that in Belarus quite a lot of attention is paid to the development of the tourism sector: business support in the creation of agro-ecotourism facilities, many modern hotels, a constant process of restoration of certain objects of architecture and art, and the like.

However, participation in exhibitions and holding competitions do not equally influence the increase in the volume of inbound tourism. This is reflected in the values of the coefficients for the corresponding variables and is also confirmed when passing to the analysis of the elasticity coefficients. We can say that most of the competitions (not taking into account such large tournaments as the European Games or the Ice Hockey World Championship) attract a narrow circle of people (mainly referees, coaches and athletes and, to a lesser extent, fans), this is due to the fact that that many fans from distant countries simply know little about the country or have some prejudices associated with staying with the country, and fans from nearby countries may have been to Belarus a long time ago. And this is where various international exhibitions come to the rescue, where members of the Belarusian delegations are able to somewhat destroy all stereotypes, show the country from its best side and interest potential tourists in trips to the Republic of Belarus. 
Due to the difficult epidemiological situation that has developed throughout the world due to the spread of the Covid-19, as well as the closure of borders, it is extremely difficult to predict what the real volume of inbound tourism in Belarus will be in 2020. But based on the data on the number of international competitions that were planned for 2020 in Belarus, as well as on the number of international exhibitions of the National Academy of Sciences of Belarus, we will calculate the number of tourists who could visit the country this year. The data for forecasting the volume of foreign tourists for 2020 for the Republic of Belarus, excluding the impact of the Covid-19, are as follows: the number of international competitions - 105 (5 more than in 2019), the number of exhibitions - 47 (4 more than in 2019). According to model (1), the estimate of the number of foreign tourists to the Republic of Belarus will be 437.3 thousand people. Based on the data obtained, we can conclude that in accordance with the previously developed model, the volume of inbound tourism should have increased by 31.83 thousand people. Of course, this forecast does not take into account many other factors that can affect this indicator.

\section{Hypothesis 2: Assessment of the Impact of Soft Power Tools on Country Indexing in Search Engines and Globalization Index}

There is no universal methodology that can be used to assess the effect of a sports event. On the one hand, one can try to estimate the number of tickets sold, the number of foreign guests who arrived, what part of the tickets was sold to foreign organizations and individuals, an increase in hotel occupancy, and an increase in prices for rental housing near the sports infrastructure. However, it is almost impossible to correlate the costs of hosting a sporting event with the additional profit that was received. One of the important effects of international sports events is an increase in interest in the country, an increase in indexing in search queries of keywords characterizing the country, improving positions in various ratings and based on indices like for example KOF Globalization Index. Many empirical studies have found confirmation of the relationship between the KOF index and indicators of economic growth, foreign trade, income inequality, etc., including on the basis of data from the Republic of Belarus [17, 18].

The research was based on the hypothesis that the holding of international sports events directly affects the increase in indexing in search queries of keywords characterizing the country, which in turn, through the components of the globalization index, has a positive effect on its value for the country. The first statement is confirmed on the basis of the analysis of the dynamics of the corresponding Google queries, which shows the growing interest in the republic on the part of the world Internet community, as measured by the Google Trend indices: the number of queries "Belarus", "Republic of Belarus", "Minsk" (in Russian and English) and some others increased significantly in the period before and during these sporting events. The correlation analysis carried out by the authors testifies in favor of the existence of a relationship between the indicators of mentioning the designated words in search engines and the KOF. The simultaneous use of all indicators related to the mention of words and phrases in search engines leads to multicollinearity and specification errors. When assessing the correlation of the considered indexes of the mention of words and phrases with the globalization index, the choice of the indicator depends on the period under consideration. The analysis also demonstrates a different functional form, depending on the choice of the indicator [19]. As part of the analysis in the developed model, the choice was made in favor of the index of mentioning "Minsk", designated further by GTI.

It follows from the description of the indicators that in this case we are talking about data of different frequencies. In the case of switching to the consideration of annual data, when average annual values are calculated for high-frequency data, the model will be built on short time series. It is allowed to estimate the annual regression using monthly high frequency 
regressors, i.e. it is possible to add each of the monthly components as a regressor, which in the case of an insufficient number of observations for KOF will also not lead to a satisfactory result. Based on the nature of the definition of the globalization index KOF, the authors decided to consider the initial data with a higher frequency, having previously confirmed the existence of a relationship based on class models MIDAS (Mixed data sampling), in order to exclude the possibility of obtaining false conclusions about the presence of a relationship. Indeed, based on the models U-MIDAS (regressions with unrestricted lag polynomials) the relationship between GTI and KOF is confirmed with $1=1,2$. Equation (2) is an estimate of the KOF Globalization Index based on an econometric model.

$$
\begin{gathered}
K O F_{t}=6.8+0.013 G I_{t}+0.883 K O F_{t-1} \quad R^{2}=0.967 \\
(0.03) \quad(0.0198) \quad(0.000)
\end{gathered}
$$

Model (2) is statistically adequate and satisfies all assumptions of the method. Similar results can be obtained for the logarithm data. The inertial nature of the globalization index is confirmed. Also, in spite of the stability of the confirmed relation, in order to increase the values of the globalization index, it is necessary that indexation in search engines increases significantly. The latter, in the case of Belarus, really happened either in connection with international sports events, or when Belarus provided a platform for government negotiations, for example, on Ukraine.

A preliminary assessment of the predictive qualities of the model was carried out on the basis of a retrospective forecast for 2017, i.e. the model was reevaluated on data up to 2016 , then the forecast was evaluated and a conclusion was made about its accuracy based on the mean relative forecast error in percentage (MAPE). Since the forecast error for twelve months of 2017 was only $0.14 \%$, this allows us to conclude that model (2) is suitable for making forecasts. According to the forecast, the value of the globalization index KOF for Belarus from 2018 to 2020 will demonstrate moderate growth $(0.5-1.5 \%)$.

\section{Conclusion}

Thus, we can say that the results of the analysis are in favor of the assumption put forward by the authors. In this case, the analysis shows that the stake placed on holding various international sports events in Belarus was correct, despite the existing criticism. International sports events attract the attention of the world community, which is reflected in an increase in search queries (indexing) in global search engines and is reflected in an increase in the values of the globalization index. The holding of international sports events affects the influx of foreign tourists into the country, leads to a steady increase in interest in the country, which in turn can affect its economic and social development. Thus, this neutral instrument of soft power can be a channel of economic, social, political influence of the host country, as well as a way to improve the country's reputation and brand.

\section{References}

1. Nye, J. S. (2011). The future of power. New York: PublicAffairs.

2. Nye, J. S. (2004). Soft power: The means to success in world politics. New York: Public Affairs.

3. Cingiene, V., Damijonaitis, M., Komskiene, D. (2014). Soft power index extension: The case of the influence of Lithuanian basketball. Transformations in Business and Economics. 13, 462-482.

4. Kaneva, N. (2011). Nation branding: Toward an agenda for critical research. International Journal of Communication. 5, 117-141. 
5. Seong-Hun, Y. (2018). An Overdue Critical Look at Soft Power Measurement: The Construct Validity of the Soft Power 30 in Focus. Journal of International and Area Studies, 25(2), 1-20.

6. Ernst \& Young. (2012). Rapid-growth markets soft power index. Retrieved from https://www.ey.com/

/Publication/vwLUAssets/Rapid-growth_markets:_Soft_power_index/\$FILE/Rapidgrowth_markets-Soft_Power_Index-Spring_2012.pdf

7. Rose, A. (2016). Like Me, Buy Me: The Effect of Soft Power on Exports. Economics and Politics, 28(2), 216-232.

8. Rose, A. (2019). Soft power and exports. Review of International Economics, 27(5), 1573-1590.

9. Didier, L. (2019). Soft power and exporters behavior in international trade. Economics Bulletin, 39(4), 2595-2614.

10. Laifer, N., Kitchen, N. (2017). Making soft power work: Theory and practice in Australia's international education policy. Politics \& Policy, 45(5), 813-840.

11. Strożek, P., Kobierecki, M.M. (2017). Sport as a Factor of Nation Branding: A Quantitative Approach. The International Journal of the History of Sport, 34(7-8), 697712.

12. Korneeva, V.A., Ogurtsov, E.S. (2016). The Politicization of Sports as a Soft Power Public Resource. Indian Journal of Science and Technology, 9(29), 697-712.

13. Grix, J., Lee, D. (2013). Soft Power, Sports Mega-Events and Emerging States: The Lure of the Politics of Attraction. Global Society, 27(4), 521-536.

14. Grix, J., \& Houlihan, B. (2014). Sports mega-events as part of a nation's soft power strategy: The cases of Germany (2006) and the UK (2012). The British journal of politics and international relations, 16(4), 572-596.

15. Grix, J., Brannagan, P.M., Lee, D. (2019). Sports Mega-Events and the Concept of Soft Power. In: Entering the Global Arena. Mega Event Planning. Palgrave Pivot, Singapore, 23-36.

16. Gates, S., Nygård, H.M. (2014). Soft Power at Home and Abroad: Sport Diplomacy, Politics and Peace-building. International Area Studies Review, 16(3), 235-243.

17. Abakumova, J.G., Primierova O.K. (2019). Globalization and Export Flows Between Eurasian Economic Union Countries: A Gravity Model Approach. Proceedings of the Globalization and its socio-economic consequences 2019 conference.

18. Abakumova, J.G., Primierova O.K. (2018). Globalization, Growth and Inequality: Testing Causality and Asymmetries. Ekonomicko-manazerske spectrum, 12(2), 83-95.

19. Pavlovskaya, S.V., Abakumova, J.G. (2020). Soft Power Evaluating the effectiveness of a neutral tool. Proceedings of the economic development trends in the 21 st century 2020 conference, 179-181. 